\title{
Molecular hydrogen produced by elemental magnesium inhibits rumen fermentation and enhances methanogenesis in dairy cows
}

\author{
Zhi Yuan Ma, ${ }^{1,2}$ Xiu Min Zhang, ${ }^{1,2}$ Min Wang, ${ }^{1 *}$ Rong Wang, ${ }^{1}$ Zai Yang Jiang, ${ }^{3,4}$ Zhi Liang Tan, ${ }^{1}$ \\ Feng Xian Gao, ${ }^{3,4}$ and Arowolo Muhammed ${ }^{1}$ \\ ${ }^{1}$ Chinese Academy of Sciences Key Laboratory for Agro-Ecological Processes in Subtropical Region, National Engineering Laboratory \\ for Pollution Control and Waste Utilization in Livestock and Poultry Production, South-Central Experimental Station of Animal Nutrition \\ and Feed Science in Ministry of Agriculture, Hunan Provincial Engineering Research Center for Healthy Livestock and Poultry Production, \\ Institute of Subtropical Agriculture, The Chinese Academy of Sciences, Changsha, Hunan 410125, P. R. China \\ ${ }^{2}$ College of Resources and Environment, University of Chinese Academy of Sciences, Beijing 100049, P. R. China \\ ${ }^{3}$ Hunan Co-Innovation Center of Animal Production Safety (CICAPS), Changsha, Hunan 410128, P. R. China \\ ${ }^{4}$ Department of Animal Science and Technology, University of Hunan Agricultural University, Changsha, Hunan 410128, P. R. China
}

\section{ABSTRACT}

Hydrogen is a key metabolite that connects microbial fermentation and methanogenesis in the rumen. This study was to investigate the effects of elevated $\mathrm{H}_{2}$ produced by elemental $\mathrm{Mg}$ on rumen fermentation and methanogenesis in dairy cows. Four nonlactating Chinese Holstein dairy cows were employed for this experiment in a replicated crossover design. The 2 dietary treatments included a basal diet supplemented with $\mathrm{Mg}(\mathrm{OH})_{2}(14.5 \mathrm{~g} / \mathrm{kg}$ of feed dry matter) or elemental $\mathrm{Mg}(6.00 \mathrm{~g} / \mathrm{kg}$ of feed dry matter). When compared with $\mathrm{Mg}(\mathrm{OH})_{2}$ treatment, cows fed diet with elemental $\mathrm{Mg}$ had similar rumen $\mathrm{Mg}^{2+}$ concentration, but higher rumen dissolved $\mathrm{H}_{2}$ and methane concentrations at 2.5 $\mathrm{h}$ after morning feeding. Also, elemental $\mathrm{Mg}$ supplementation decreased feed digestibility, rumen volatile fatty acid concentration, and relative abundance of group Ruminococcaceae_UCG-014, genus Bifidobacterium, and group Mollicutes_RF9, increased acetate to propionate ratio, succinate concentration, and abundance of family Christensenellaceae. Elemental $\mathrm{Mg}$ supplementation increased enteric $\mathrm{CH}_{4}$ emission, altered methanogen community with increased abundance of order Methanomassiliicoccales, 16S ribosomal RNA gene copies of methanogens, and order Methanobacteriales. In summary, the pulse of elevated dissolved $\mathrm{H}_{2}$ after feeding produced by elemental $\mathrm{Mg}$ inhibited rumen fermentation and feed digestibility by decreasing the abundance of carbohydrate-degrading bacteria, promoted $\mathrm{H}_{2}$ incorporation into succinate by increasing family Christensenellaceae and genus Bacteroidales_

Received September 4, 2018.

Accepted February 26, 2019.

*Corresponding author: mwang@isa.ac.cn
$B S 11$, and increased $\mathrm{H}_{2}$ utilization for methanogenesis by favoring growth of methanogens.

Key words: elemental magnesium, dissolved hydrogen, feed digestibility, rumen fermentation, methanogenesis

\section{INTRODUCTION}

Molecular hydrogen is mainly produced by carbohydrate fermentation and then used by methanogens to produce $\mathrm{CH}_{4}$ in the rumen (Hungate, 1967; Robinson and Tiedje, 1982). Starch in concentrate diets has greater and faster rumen degradability than fiber in forage and produces a large amount of $\mathrm{H}_{2}$ (Wang et al., 2016b). Also, high dietary starch has been observed to cause a reduction in rumen fiber digestibility in vitro (Grant and Mertens, 1992) and in vivo (Yang et al., 2001). Methanogenesis is the largest $\mathrm{H}_{2}$ sink in the rumen and maintains low $\mathrm{H}_{2}$ partial pressures, which in turn promotes re-oxidization of NADH/NADPH and supports continuous fermentation processes (Robinson and Tiedje, 1982). When methanogenesis is inhibited, rumen $\mathrm{H}_{2}$ accumulates followed by a reduction in rumen fermentation and feed degradation (Goel and Makkar, 2012; Ungerfeld, 2015). This shows that increased rumen $\mathrm{H}_{2}$ is associated with the inhibition of rumen fermentation and feed degradation.

Rumen $\mathrm{H}_{2}$ has been proposed to influence the fermentation pathways thermodynamically, and increased $\mathrm{H}_{2}$ partial pressure can inhibit NADH/NADPH generation and decrease the acetate to propionate ratio (Ungerfeld and Kohn, 2006; Janssen, 2010). However, rumen $\mathrm{H}_{2}$ may not always be associated with shifts in fermentation pathways. For example, Wenner et al. (2017) reported that increased passage rate does not alter rumen $\mathrm{H}_{2}$, but shifts acetate toward propionate production. Wang et al. (2018) reported that increased rumen $\mathrm{H}_{2}$ is not associated with changes of VFA profiles in goats 
fed high starch. Martinez-Fernandez et al. (2018) reported 3-NOP supplementation did not influence $\mathrm{H}_{2}$ gas emissions but facilitated acetate production in beef steers. Further studies are still needed to investigate the relationship between rumen $\mathrm{H}_{2}$, fermentation pathways and associated microbiota in vivo.

Rumen methanogenesis mainly involves 3 types of methanogenic metabolic pathways, which includes hydrogenotrophic (reduction of $\mathrm{CO}_{2}$ coupled to the oxidation of $\mathrm{H}_{2}$ ), methylotrophic (conversion of methyl-group containing compounds), and acetoclastic pathways (Lovley and Ferry, 1985; Rother and Krzycki, 2010). The hydrogenotrophic pathway accounts for the first dominant metabolic pathway of methanogenesis in the rumen (Hungate, 1967; Hook et al., 2010). Increasing rumen $\mathrm{H}_{2}$ may enhance the hydrogenotrophic methanogenesis, and thus affect $\mathrm{H}_{2}$ utilization and methanogen communities in the rumen.

Rumen $\mathrm{H}_{2}$ exists in 2 forms: the gaseous $\mathrm{H}_{2}$ and the dissolved $\mathrm{H}_{2}\left(\mathbf{d H}_{\mathbf{2}}\right)$, and only the $\mathrm{dH}_{2}$ is biologically relevant for rumen microorganisms (Wang et al., 2016a). Elemental Mg supplementation previously increased rumen $\mathrm{dH}_{2}$ concentration and influenced rumen fermentation and $\mathrm{CH}_{4}$ emission in goats (Wang et al., 2017). Interestingly, elemental $\mathrm{Mg}$ tends to react with $\mathrm{H}^{+}$in rumen fluid to produce extra $\mathrm{H}_{2}$ according to the reaction $\mathrm{Mg}+2 \mathrm{H}^{+} \rightarrow \mathrm{Mg}^{2+}+\mathrm{H}_{2}$ to produce $\mathrm{H}_{2}$. Studies are needed to comprehensively investigate the biological function of $\mathrm{dH}_{2}$ in dairy cows. In this experiment, $\mathrm{Mg}$ was added to TMR to increase $\mathrm{dH}_{2}$, whereas $\mathrm{Mg}(\mathrm{OH})_{2}$ was included as the control group, because $\mathrm{Mg}(\mathrm{OH})_{2}$ can also react with ruminal $\mathrm{H}^{+}$according to the reaction $\mathrm{Mg}(\mathrm{OH})_{2}+2 \mathrm{H}^{+} \rightarrow \mathrm{Mg}^{2+}+2 \mathrm{H}_{2} \mathrm{O}$. Therefore, we hypothesized that elemental $\mathrm{Mg}$, compared with $\mathrm{Mg}(\mathrm{OH})_{2}$ supplementation, could increase $\mathrm{dH}_{2}$ concentration in the liquid phase of the rumen, which would influence feed digestibility, rumen fermentation, methanogenesis, and microbiota in dairy cows.

\section{MATERIALS AND METHODS}

All animal procedures followed our institutional guidelines for the care and use of animals and were approved by the Animal Care Committee (approval number ISA-W-201702), Institute of Subtropical Agriculture, the Chinese Academy of Sciences, Changsha, China.

\section{Experimental Design and Animals}

Four nonlactating Chinese Holstein rumen-fistulated dairy cows of about $7 \mathrm{yr}$ of age $(\mathrm{BW}=503.3 \pm 83.21$ $\mathrm{kg}$, DMI $=7.0 \pm 1.12 \mathrm{~kg}$, daily $\mathrm{CH}_{4}$ emission $=175.4$
Table 1. Ingredients and chemical compositions of basal diet

\begin{tabular}{lc}
\hline Item & Value \\
\hline Ingredient, g/kg & \\
Corn silage & 500 \\
Corn & 142 \\
Soybean meal & 115 \\
Wheat middlings & 100 \\
Wheat bran & 100 \\
Palm fat powder & 10 \\
Limestone & 8 \\
Calcium hydrophosphate & 5 \\
Urea & 5 \\
Sodium chloride & 5 \\
Vitamin/trace mineral premix ${ }^{2}$ & 10 \\
Chemical composition, g/kg & \\
CP & 145 \\
NDF & 435 \\
ADF & 211 \\
Starch & 216 \\
Ash & 155 \\
DE ${ }^{3}$ MJ/kg of DM & 14.1 \\
\hline
\end{tabular}

${ }^{1}$ The limestone included $38.4 \% \mathrm{Ca}$ and $0.8 \% \mathrm{Mg}$.

${ }^{2}$ Premix provided per kilogram of concentrate: 1,000,000 IU of vitamin A, 200,000 IU of vitamin D, 1,250 IU of vitamin E, 8,000 mg of Zn, 80 $\mathrm{mg}$ of Se, $120 \mathrm{mg}$ of I, 2,000 $\mathrm{mg}$ of Fe, $40 \mathrm{mg}$ of Co, 2,500 mg of Mn, and $2,000 \mathrm{mg}$ of $\mathrm{Cu}$.

${ }^{3} \mathrm{DE}=$ digestible energy, calculated according to NRC (2001).

$\pm 12.07 \mathrm{~g}$; mean $\pm \mathrm{SD}$ ) were used for this experiment. The experiment was a replicated crossover design with 2 dietary treatments, which were a basal diet (Table 1) supplemented with $\mathrm{Mg}(\mathrm{OH})_{2}(14.5 \mathrm{~g} / \mathrm{kg}$ of $\mathrm{DM})$ or elemental $\mathrm{Mg}(6.00 \mathrm{~g} / \mathrm{kg}$ of DM).

Cows were housed in a tiestall barn and fed individually at 0630 and $1630 \mathrm{~h}$. All cows had free access to fresh water. The TMR provided allowed less than $1 \%$ of feed refusal to ensure the similar DMI $[7.06 \pm$ $1.30 \mathrm{~kg} / \mathrm{d}$ for $\mathrm{Mg}(\mathrm{OH})_{2}$ treatment; $7.08 \pm 0.96 \mathrm{~kg} / \mathrm{d}$ for elemental $\mathrm{Mg}$ treatment; mean $\pm \mathrm{SD}$ ] of 2 groups. In each experimental period, $30 \mathrm{~d}$ in total, cows passed through $15 \mathrm{~d}$ of diet adaptation, $5 \mathrm{~d}$ of feces and diet refusal collection, $8 \mathrm{~d}$ for measuring $\mathrm{CH}_{4}$ emissions $(2 \mathrm{~d}$ in a respiration chamber for 4 cows), and $2 \mathrm{~d}$ of rumen content collection.

\section{Nutrient Digestibility}

Total feces and feed refusals were collected for 5 consecutive days and processed according to the procedure described by Wang et al. (2016b). The DM (method 934.01), ash (method 942.05), and CP (method 990.03) were determined according to AOAC (1990). The NDF and ADF were measured following the procedures of Van Soest et al. (1991) by using a Fibertherm analyzer (C. Gerhardt Ins., Königswinter, Germany) and expressed inclusive of residual ash. The $\alpha$-amylase and 
sodium sulfite (Sigma, Shanghai, China) were added to remove starch and protein within NDF analysis. The starch content was determined after pre-extraction with $80 \%$ ethanol ( $\mathrm{vol} / \mathrm{vol}$ ), and glucose released from starch by enzyme hydrolysis was measured using amyloglucosidase (Sigma) according to Karthner and Theurer (1981). Gross energy was measured with an automatic calorimeter (5E-AC8018, Changsha Kaiyuan Instruments Co. Ltd., Changsha, China).

\section{Methane Emissions}

Four cows of each experimental period were sequenced individually through the respiration chamber by 2 blocks. Each block of 2 cows contained 1 cow from 2 treatments, and emissions from each cow were measured for $2 \mathrm{~d}$. Thus, 4 cows were passed through the chamber within $8 \mathrm{~d}$.

Methane recovery was valid before and after measurement, and a correction factor was then developed by comparing the amount of pure $\mathrm{CH}_{4}$ released into the empty chamber with measured flux of $\mathrm{CH}_{4}$ from the chamber. Methane emissions from each cow were measured in a respiration chamber using the protocol by Wang et al. (2015). Airflow was maintained under negative chamber pressure (flow rate $=190 \pm 2 \mathrm{~m}^{3} / \mathrm{h}$ ), controlled by an air pump. The outlet gas from the chamber and ambient gas were connected to a Multiport Inlet Unit of the Gas Analyzer (GGA-30p, Los Gatos Research, CA) using 1/8 inch $(0.32 \mathrm{~cm})$ polyurethane tubing. Methane concentration in the chamber and ambient gas was recorded every $30 \mathrm{~min}$. The amount of daily $\mathrm{CH}_{4}$ emissions was then calculated by multiplying correction factor and measured flux of $\mathrm{CH}_{4}$ from chamber. Staff entered each chamber twice daily at 0530 and $1530 \mathrm{~h}$ for approximately $20 \mathrm{~min}$ for feeding. Within the chamber, cows were restrained in the bin with free access to drinking water.

\section{Rumen Sampling and Analysis}

Rumen contents were sampled from the middle of the ventral sac for $2 \mathrm{~d}$ after $\mathrm{CH}_{4}$ measurement through a rumen cannula at $0,2.5$, and $6 \mathrm{~h}$ after the morning feeding. One subsample $(100 \mathrm{~mL})$ was immediately frozen in liquid nitrogen and stored at $-80^{\circ} \mathrm{C}$ for subsequent DNA extraction and quantification of microbial groups. Rumen fluids were immediately separated from rumen contents by squeezing through cheesecloths (350 $\mu \mathrm{m}$, Tang Rong Medical Supplies Co. Ltd., Yangzhou, China). Because the mesh size of cheesecloth we used was higher than the $250 \mu \mathrm{m}$ reported in the literature (Maekawa et al., 2002), 6 layers rather than the typical 4 layers of cheesecloths were conducted to filter rumen fluids. Two other subsamples (35 $\mathrm{mL}$ each) of rumen fluid were immediately transferred into $50-\mathrm{mL}$ plastic syringes for the measurement of $\mathrm{dH}_{2}$ and dissolved methane $\left(\mathbf{d C H}_{\mathbf{4}}\right)$ concentration. About $20 \mathrm{~mL}$ of rumen fluids were used for immediate measurement of rumen $\mathrm{pH}$ by using a portable $\mathrm{pH}$ meter (Starter 300, Ohaus Instruments Co. Ltd., Shanghai, China), calibrated before each sampling using standard buffers $(\mathrm{pH}$ 4.0 and 7.0). Samples of $2 \mathrm{~mL}$ of rumen fluid were centrifuged at $12,000 \times g$ for $10 \mathrm{~min}$ at $4^{\circ} \mathrm{C}$, and aliquots of the supernatants $(1.5 \mathrm{~mL})$ were transferred into plastic tubes each containing $0.15 \mathrm{~mL}$ of $25 \%$ (wt/vol) metaphosphoric acid and stored at $-20^{\circ} \mathrm{C}$ overnight for subsequent measurement of VFA and ammonia. The remaining samples $(50 \mathrm{~mL})$ were stored at $-20^{\circ} \mathrm{C}$ for measuring $\mathrm{Mg}^{2+}$, formate, and succinate.

Dissolved $\mathrm{CH}_{4}$ and $\mathrm{dH}_{2}$ in rumen fluid were extracted according to the protocol of Wang et al. (2014). In brief, an approximately $35-\mathrm{mL}$ subsample of rumen fluid was quickly transferred into a $50-\mathrm{mL}$ plastic syringe, which was connected with a $20-\mathrm{mL}$ syringe filled with $10 \mathrm{~mL}$ of $\mathrm{N}_{2}$. Nitrogen gas was then injected into the 50 -mL syringe via polyurethane tubing, and the gases dissolved in the rumen fluid were extracted into the $\mathrm{N}_{2}$ gas phase by shaking in an orbital shaker (Wuhan Huichen Biotech Co., Wuhan, China) at a speed of 200 rpm for 5 min. Extracted gas samples were collected in evacuated tubes, and concentrations of $\mathrm{CH}_{4}$ and $\mathrm{H}_{2}$ were measured by using GLC (Agilent 7890A, Agilent Inc., Palo Alto, CA). The standard gas concentration $(\mathrm{L} / \mathrm{L})$ grades were $0.1,0.01$, and $0.001 \%$ for $\mathrm{H}_{2}$ and $10,5,1$, and $0.5 \%$ for $\mathrm{CH}_{4}$. All standard gases were prepared and qualified by Aerospace Ruida Standard Material Technology (Beijing) Co. Ltd. Concentrations of $\mathrm{dH}_{2}$ and $\mathrm{dCH}_{4}$ in the original liquid fraction were calculated according to equations described in Wang et al. (2016a).

The concentration of $\mathrm{Mg}^{2+}$ was determined by Inductively Coupled Plasma-Optical Emission Spectrometers using Varian 720-ES (Agilent Inc.) as described by Wang et al. (2017). Individual VFA concentrations were analyzed using gas-liquid chromatography (Agilent 7890A, Agilent Inc.) according to the procedure of Wang et al. (2016a). Ammonia concentration was measured using the procedure of Shahinian and Reinhold (1971). The formate and succinate were measured using HPLC (Agilent 1260, Agilent Inc.) according to the procedure described by Gagen et al. (2014).

\section{Pyrosequencing of 16S rRNA Gene Amplicons}

Microbial DNA was extracted according to the protocol described by $\mathrm{Yu}$ and Morrison (2004), with the exception that DNA was purified by phenol/chlo- 
roform/isopentyl alcohol (25:24:1 vol/vol/vol, Solarbio Co., Shanghai, China) as described by Minas et al. (2011), then the vacuum-dried DNA pellets were dissolved in Tris EDTA buffer (Tris $10 \mathrm{~m} M$, EDTA 1 $\mathrm{m} M, \mathrm{pH}=8.0)$ after being washed with $70 \%$ ethanol alcohol twice. The concentration and purity of DNA were measured using an ND-2000 spectrophotometer (NanoDrop Technologies, Wilmington, DE). The $16 \mathrm{~S}$ rRNA gene amplicons were produced as described in our previous work (Ma et al., 2018) and were sequenced with the Illumina MiSeq platform by Majorbio BioPham Technology, Shanghai, China. Primers for bacterial and methanogens amplicons are shown in Table 2. Raw reads were submitted to the NCBI Sequence Read Archive (https://www.ncbi.nlm.nih.gov/sra) database under accession number SRP149140. Quality control of the sequence reads was performed using the MOTHUR v.1.40 (Schloss et al., 2009) and followed the protocol described by Kozich et al. (2013). Reads were clustered into operational taxonomic units at $97 \%$ similarity, and the data were normalized according to the samples with the smallest number of reads. Taxonomic analysis was carried out using the RDP classifier v.11.1 (Wang et al., 2007) with a minimum support threshold of $80 \%$ against the SILVA.nr.132 database including 188,247 bacteria, 4,626 archaea, and 20,246 eukarya sequences (Quast et al., 2013). A principal coordinate analysis was performed based on Bray-Curtis similarity distances (Bray and Curtis, 1957).

\section{Quantitative Real-Time PCR Analyses}

The absolute quantification of total methanogens, order Methanobacteriales, and genus Methanobrevibacter was measured by quantitative real-time PCR (qPCR) with primers validated in our laboratory (Table 2). Quantitative PCR assays were performed according to the procedures described by Ma et al. (2018) by using a LightCycler 480 (Roche Molecular Systems Inc., Pleasanton, CA) and qPCR SuperMix (Transgen, Bei- jing, China). Final absolute amounts of target groups were estimated by relating the cycle threshold value to standard curves and expressed as copies per milliliter of rumen fluid ( $\log _{10}$ transformed).

\section{Statistical Analyses}

Statistical analyses were performed using a linear mixed model of SPSS 17.0 software (SPSS Inc., Chicago, IL). The first analytic model included treatment as a fixed effect, and animal, period, and block as random effects. When sampling time was considered, the second analytic model was used to include treatment, an interaction of treatment and sampling time as the fixed effect, sampling time as a repeated measurement, and animal, period, and block as the random effect. When significant interaction of treatment and sampling time was observed, statistical analysis was re-performed for each sampling time point by using the first model. Statistical significance of effects was declared at $P \leq$ 0.05 and a tendency at $0.05<P \leq 0.10$.

\section{RESULTS}

Elemental $\mathrm{Mg}$ supplementation decreased $(P=$ 0.018; Table 3) total-tract OM digestibility in dairy cows. Compared with cows fed diet with $\mathrm{Mg}(\mathrm{OH})_{2}$, cows supplemented with elemental $\mathrm{Mg}$ had greater enteric $\mathrm{CH}_{4}$ emission in terms of grams per day $(+37.2 \%$, $P=0.09), \mathrm{g} / \mathrm{kg}$ of DMI $(+33.8 \%, P=0.003), \mathrm{g} / \mathrm{kg}$ of OM digested $(+48.7 \%, P=0.002)$, and $\mathrm{g} / \mathrm{kg}$ of $\mathrm{NDF}$ digested $(+48.0 \%, P=0.005)$.

Concentrations of $\mathrm{Mg}^{2+}$ and ammonia, and $\mathrm{pH}$ in the rumen of cows fed diets with elemental $\mathrm{Mg}$ did not differ significantly $(P \geq 0.41$; Table 4$)$ to cows fed diet with $\mathrm{Mg}(\mathrm{OH})_{2}$. Interactions between treatment and time were observed for rumen $\mathrm{dH}_{2}(P=0.005)$ and $\mathrm{dCH}_{4}(P=0.003)$ concentrations. Elemental $\mathrm{Mg}$ supplementation greatly increased $\mathrm{dH}_{2}(+129.6 \%, P=$ $0.007)$ and $\mathrm{dCH}_{4}(+110.8 \%, P=0.024)$ in rumen fluid

Table 2. Primers for amplicons and quantitative real-time PCR (qPCR) of microbial groups

\begin{tabular}{llll}
\hline Microbial group & Primer & Sequence $\left(5^{\prime} \rightarrow 3^{\prime}\right)$ & Reference \\
\hline Amplicons & Forward & ACTCCTACGGGAGGCAGCA & Amato et al. (2013) \\
Bacteria & Reverse & GGACTACHVGGGTWTCTAAT & Pires et al. (2012) \\
Methanogens & Forward & TGYCAGCCGCCGCGGTAA & \\
Reverse & YCCGGCGTTGAVTCCAATT & Denman and McSweeney (2006) \\
Total methanogens & Forward & GGATTAGATACCCSGGTAGT & Yu et al. $(2005)$ \\
Methanobacteriales & Reverse & GTTGARTCCAATTAAACCGCA & Huang et al. $(2016)$ \\
Methanobrevibacter & Reverse & TACAGGGAAGCTGTTAAGT & \\
& Forward & CCTCCGCATCCACTCCTT & \\
\hline
\end{tabular}


Table 3. Feed intake and digestibility and methane emission in dairy cows fed a diet with $\operatorname{Mg}(\mathrm{OH})_{2}$ or elemental $\mathrm{Mg}(\mathrm{n}=4)$

\begin{tabular}{|c|c|c|c|c|}
\hline \multirow[b]{2}{*}{ Item } & \multicolumn{2}{|c|}{ Treatment } & \multirow[b]{2}{*}{ SEM } & \multirow[b]{2}{*}{$P$-value } \\
\hline & $\mathrm{Mg}(\mathrm{OH})_{2}$ & $\mathrm{Mg}$ & & \\
\hline DMI, kg & 7.08 & 7.06 & - & - \\
\hline \multicolumn{5}{|l|}{ Apparent total-tract digestibility, $\mathrm{g} / \mathrm{kg}$} \\
\hline DM & 713 & 690 & 3.0 & 0.063 \\
\hline $\mathrm{OM}$ & 716 & 690 & 1.8 & 0.018 \\
\hline $\mathrm{CP}$ & 800 & 780 & 2.2 & 0.097 \\
\hline $\mathrm{NDF}$ & 637 & 586 & 5.5 & 0.066 \\
\hline $\mathrm{ADF}$ & 598 & 536 & 3.1 & 0.014 \\
\hline Starch & 991 & 996 & 0.17 & 0.29 \\
\hline Gross energy, $\%$ & 74.1 & 72.0 & 0.22 & 0.044 \\
\hline \multicolumn{5}{|l|}{ Methane emissions } \\
\hline $\mathrm{g} / \mathrm{d}$ & 148 & 203 & 8.9 & 0.09 \\
\hline $\mathrm{g} / \mathrm{kg}$ of DMI & 21.6 & 28.9 & 0.21 & 0.003 \\
\hline $\mathrm{g} / \mathrm{kg}$ of $\mathrm{OM}$ digested & 35.1 & 49.7 & 0.29 & 0.002 \\
\hline $\mathrm{g} / \mathrm{kg}$ of NDF digested & 77.1 & 114.1 & 1.26 & 0.005 \\
\hline
\end{tabular}

collected at $2.5 \mathrm{~h}$ after morning feeding (Figure 1). Elemental Mg supplementation decreased total VFA concentration $(-11.1 \%, P=0.029)$, and increased acetate to propionate ratio $(+15.3 \%, P=0.011)$ and succinate concentration $(+265 \%, P=0.054)$ in the rumen (Table 4).

Bacteria and methanogens community were further analyzed by high-throughput sequencing. The principal coordinate analysis result of bacteria showed that cow 1 was distinctly different from the other 3 cows (Figure $2 \mathrm{~A})$. A total of 194 bacteria genera were annotated, and 22 genera with abundances larger than $1 \%$ accounted for $76.7 \%$ of total sequences (Table 5). Elemental $\mathrm{Mg}$ supplementation decreased the relative abundance of the Ruminococcaceae_UCG-014 group $(-51.8 \%, P=$
0.040), genus Bifidobacterium $(-61.4 \%, P=0.051)$ and the norank_o__Mollicutes_RF9 group $(-33.3 \%$, $P=0.024)$, but increased the relative abundance of the Ruminococcaceae_UCG-010 group $(+60.0 \%, P=$ $0.005)$, norank_f_Bacteroidales_BS11 group $(+71.2 \%$, $P=0.032)$, and family Christensenellaceae $(+57.0 \%$, $P=0.034)$ in rumen. Cow 1 had distinctly different methanogen communities from cow 3 and 4, although we did not find a separation in methanogen communities between the 2 treatments (Figure 2B). Cows fed the diet with elemental $\mathrm{Mg}$ had lower abundance of order Methanobacteriales $(P=0.005)$, and greater abundance of order Methanomassiliicoccales $(P=0.007)$ in the rumen (Table 6). The $\mathrm{qPCR}$ results showed that elemental $\mathrm{Mg}$ supplementation increased $(P \leq 0.005)$

Table 4. Dissolved gases and fermentation end products in the rumen of dairy cows fed a diet with $\mathrm{Mg}(\mathrm{OH})_{2}$ or elemental $\mathrm{Mg}(\mathrm{n}=4)$

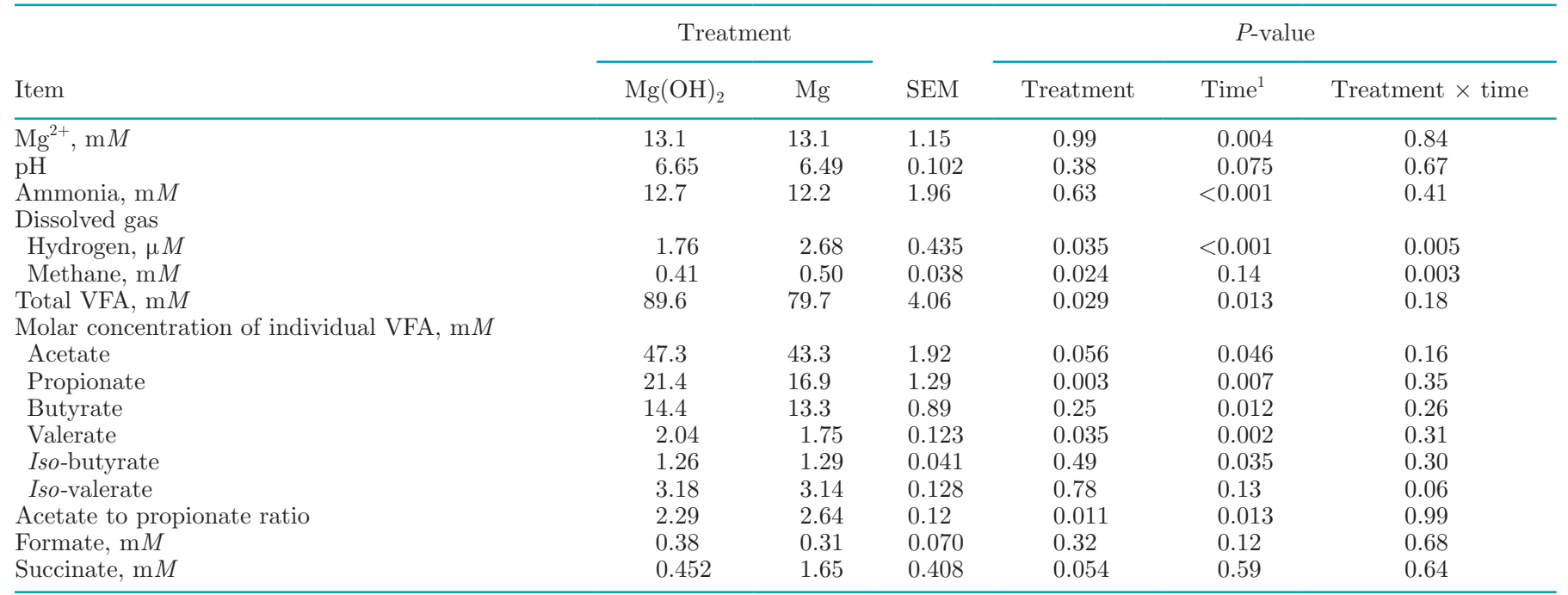

${ }^{1}$ Relative time after morning feeding. 

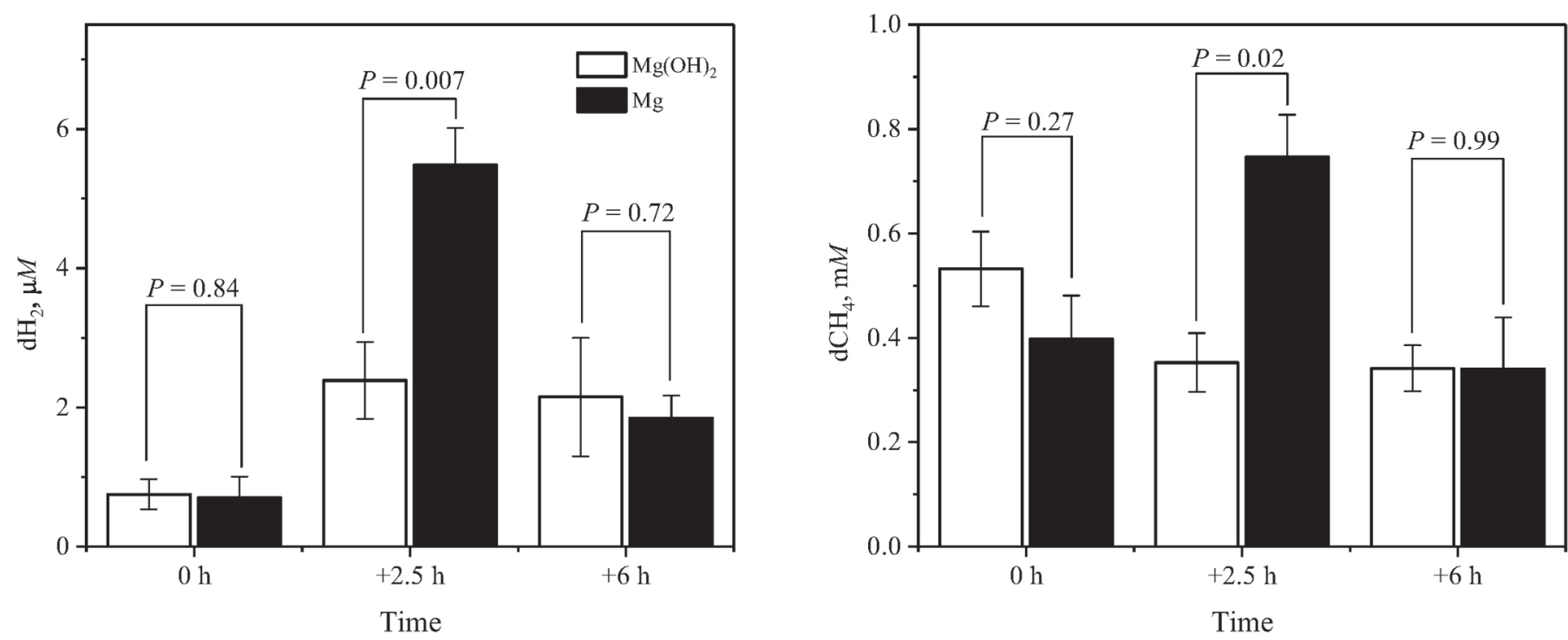

Figure 1. Dissolved hydrogen $\left(\mathrm{dH}_{2}\right)$ and methane $\left(\mathrm{dCH}_{4}\right)$ in the rumen fluids collected at $0,2.5$, and $6 \mathrm{~h}$ after morning feeding in dairy cows fed diets with $\mathrm{Mg}(\mathrm{OH})_{2}$ or elemental $\mathrm{Mg}(\mathrm{n}=4)$. Error bars show SD.

16S rRNA gene copies of methanogens and abundance of order Methanobacteriales (Table 6).

\section{DISCUSSION}

The $6 \mathrm{~g} / \mathrm{kg}$ of dietary $\mathrm{Mg}$ supplementation was relatively high but within the safe dose $(\leq 7 \mathrm{~g} / \mathrm{kg})$ reported by Quillian et al. (1980). No diarrhea occurred in any of the animals used. Both elemental $\mathrm{Mg}$ and $\mathrm{Mg}(\mathrm{OH})_{2}$ can be converted to $\mathrm{Mg}^{2+}$ in the liquid phase of the rumen, producing $\mathrm{H}_{2}$ and $\mathrm{H}_{2} \mathrm{O}$ as end products, respectively. Compared with cows fed the diet with $\mathrm{Mg}(\mathrm{OH})_{2}$, cows fed the diet with elemental $\mathrm{Mg}$ had similar $\mathrm{Mg}^{2+}$ concentration and greater $\mathrm{dH}_{2}$ concentration. Elemental $\mathrm{Mg}$ supplementation also increases ruminal $\mathrm{dH}_{2}$ concentration in goats (Wang et al., 2017). The elemental $\mathrm{Mg}$ supplementation only increased $\mathrm{dH}_{2}$ concentration at $2.5 \mathrm{~h}$ after morning feeding, whereas $\mathrm{dH}_{2}$ concentrations of the $\mathrm{Mg}$ treatment returned to the same level as the $\mathrm{Mg}(\mathrm{OH})_{2}$ treatment at $6 \mathrm{~h}$ after morning feeding. The rumen $\mathrm{dH}_{2}$ concentration can be affected by many factors, such as exhausting $\mathrm{H}_{2}$ production during the reaction of elemental $\mathrm{Mg}$ with $\mathrm{H}^{+}$and the consumption of elevated $\mathrm{H}_{2}$ by increased $\mathrm{H}_{2}$ users.

The increase in partial pressure of $\mathrm{H}_{2}$ can prevent the oxidation of $\mathrm{NADH}$ to $\mathrm{NAD}^{+}$, and thus inhibits rumen fermentation (Miller and Wolin, 1995). In addition, increased $\mathrm{H}_{2}$ is suggested to be linked with reduction in rumen fermentation and feed digestibility (Goel and Makkar, 2012; Ungerfeld, 2015). Elemental $\mathrm{Mg}$ supplementation decreased OM digestibility and total VFA concentration, which could also be caused by the extra $\mathrm{H}_{2}$ produced by elemental $\mathrm{Mg}$. Inhibition of rumen fermentation can be associated with a shift in the bacterial community (Weimer, 1998). Compared with the control group, elemental $\mathrm{Mg}$ supplementation decreased the relative abundance of the Prevotellaceae_UCG-001 group, Ruminococcaceae_UCG-014 group, Mollicutes_RF9 group, and genus Bifidobacterium. The Prevotellaceae_UCG-001 group is a hemicellulose degrader (Thoetkiattikul et al., 2013; He et al., 2017). Members of the Ruminococcaceae_UCG-014 group can also be essential fiber degraders, as its abundance is positively associated with dietary NDF intake (Zhang and Wang, 2018). The metagenome-assembled genomes of the Mollicutes_RF9 group have the CAZme associated with degrading starch (Svartstrom et al., 2017). Although genus Bifidobacterium cannot degrade polysaccharide, it synergizes with starch degraders, as genus Bifidobacterium is increased by feeding starchy diet (Trovatelli and Matteuzzi, 1976). It seems that elevated $\mathrm{dH}_{2}$ caused by elemental $\mathrm{Mg}$ supplementation inhibits some groups of carbohydrate-degrading bacteria. However, elemental $\mathrm{Mg}$ supplementation increased the relative abundance of the Ruminococcaceae_UCG-010 group, which also belongs to the family Ruminococcaceae. Unfortunately, group Ruminococcaceae_UCG-010 is an uncultured bacterium, and its biological function and ecological role in rumen need further investigation.

Fermentation of glucose to acetate and propionate involves net $\mathrm{H}_{2}$ production and incorporation, respectively (Janssen, 2010). When $\mathrm{H}_{2}$ is accumulated in the rumen, fermentation theoretically favors propionate production other than acetate production (Ungerfeld, 
2013). A negative correlation was observed between $\mathrm{dH}_{2}$ and propionate molar proportion (Wang et al., 2016b, 2017). However, our study indicated that elevated $\mathrm{dH}_{2}$ caused by elemental $\mathrm{Mg}$ supplementation increased acetate to propionate ratio in dairy cows. We suspect that other $\mathrm{H}_{2}$ sinks may be promoted, as the complex rumen microbial ecosystem can cope with elevated $\mathrm{H}_{2}$ in the rumen (Ungerfeld, 2015; Wang et al., 2017).
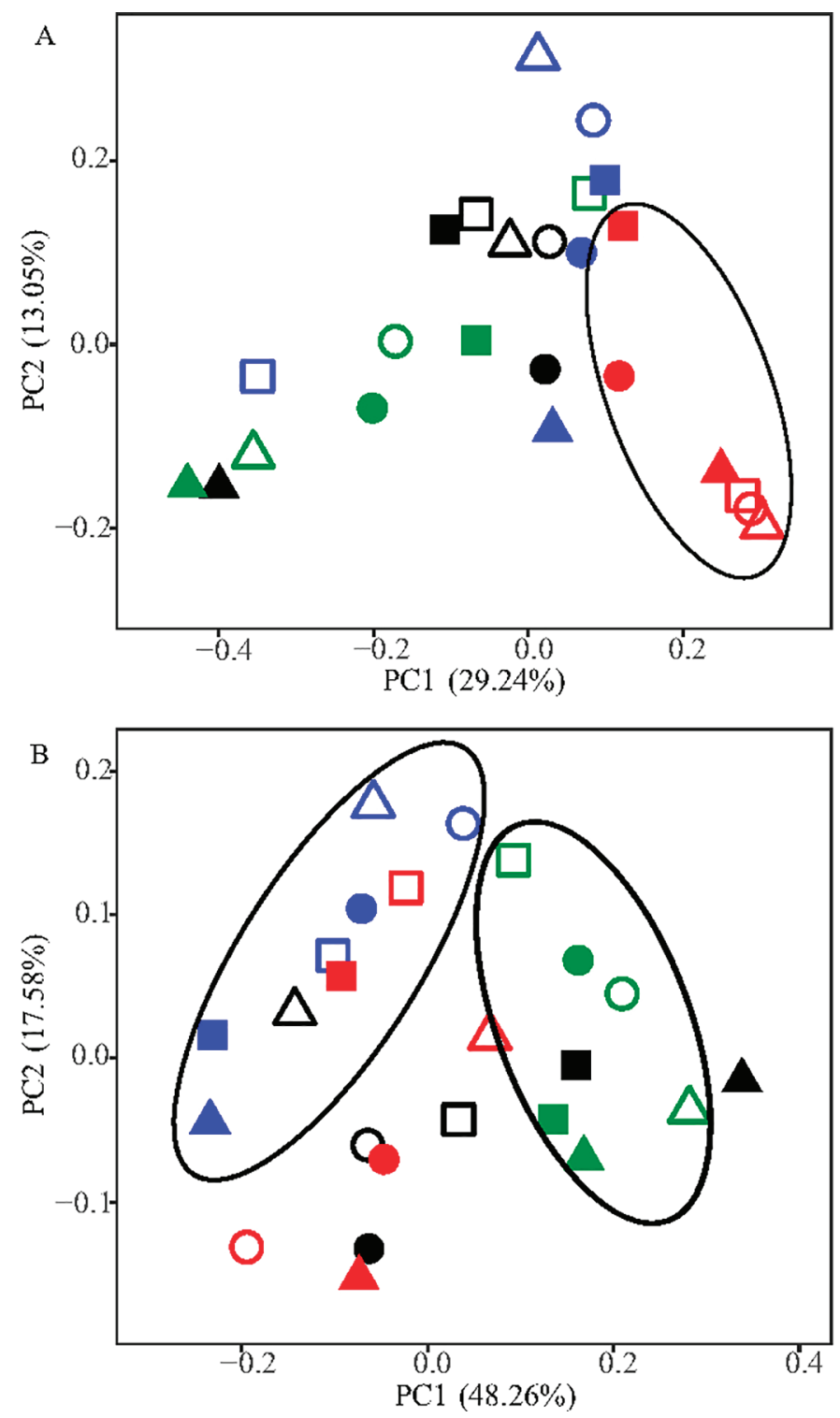

Figure 2. Principal coordinate (PC) analysis plot of the bacteria (A) and methanogen (B) community at the operational taxonomic unit level based on Bray-Curtis distances. Hollow and solid symbols indicate $\mathrm{Mg}(\mathrm{OH})_{2}$ and elemental $\mathrm{Mg}$ treatment, respectively; circle $(\bigcirc)$, triangle $(\Delta)$, and square $(\square)$ represent samples collected at 0 2.5 , and $6 \mathrm{~h}$ after morning feeding, respectively; red, black, green, and blue represent dairy cow $1,2,3$, and 4, respectively; and solid circles indicate separation in bacteria and methanogen community of cows from each other.
Succinate is an essential precursor of propionate and can be an $\mathrm{H}_{2}$ sink (Blackburn and Hungate, 1963). Formation of succinate from pyruvate involves 2 steps of metabolic hydrogen incorporation, which are oxaloacetate to malate (Kyoto Encyclopedia of Genes and Genomes reaction: R00342, www.kegg.jp) and fumarate to succinate (Kyoto Encyclopedia of Genes and Genomes reaction: R00402). Elemental Mg supplementation increased succinate concentration and decreased propionate concentration, indicating an enhancement of succinate formation or inhibition of succinate decarboxylation to propionate. The Bacteroidales_BS11 group belongs to succinate producers because it produces succinate dehydrogenase, an enzyme catalyzing the reaction of fumarate to succinate (Solden et al., 2017). Furthermore, fumarate plus malate supplementation facilitate the growth of the family Christensenellaceae (De Nardi et al., 2016), which can also be related to succinate formation according to the fermentation pathways of fumarate or malate degrading to propionate. Elemental $\mathrm{Mg}$ supplementation increased the relative abundance of the Bacteroidales_BS11 group and family Christensenellaceae, which may contribute to the accumulation of succinate.

Formate formation and methanogenesis are other important $\mathrm{H}_{2}$ sinks in the rumen. Elemental $\mathrm{Mg}$ supplementation did not alter formate concentration, indicating that elevated $\mathrm{dH}_{2}$ concentration did not change ruminal formate metabolism. However, elemental $\mathrm{Mg}$ supplementation increased the $\mathrm{dCH}_{4}$ concentration and $\mathrm{CH}_{4}$ emissions, suggesting that elevated $\mathrm{dH}_{2}$ enhances rumen methanogenesis. Similarly, previous studies also reported that $\mathrm{H}_{2}$ gas infusion promotes $\mathrm{CH}_{4}$ production in vitro (Hungate, 1967; Qiao et al., 2015) and in vivo (Olijhoek et al., 2016; Wang et al., 2017). In our study, $2 \mathrm{~mol}$ of $\mathrm{Mg}$ supplemented theoretically produces 0.5 mol of $\mathrm{CH}_{4}$, which accounted for about $15 \%$ of extra $\mathrm{CH}_{4}$ production, so the extent of increase in $\mathrm{CH}_{4}$ emissions observed $(3.4 \mathrm{~mol})$ was beyond our expectations. Elemental Mg supplementation increased population of methanogens, which could use more $\mathrm{H}_{2}$ and compete more successfully with propionate producers for the $\mathrm{H}_{2}$. Increased methanogens may also use $\mathrm{H}_{2}$ coming from other unknown sources, which needs further verification.

The methanogen community can be divided into 3 categories: hydrogenotrophic, methylotrophic, and acetoclastic methanogens. Genus Methanobrevibacter belongs to hydrogenotrophic methanogens and can reduce $\mathrm{CO}_{2}$ coupled to the oxidation of $\mathrm{H}_{2}$ to produce $\mathrm{CH}_{4}$. Kim (2012) reported that Methanobrevibacter are more competitively successful than other genera under high $\mathrm{H}_{2}$ partial pressure in the rumen. This is not the case in our study. Although elevated $\mathrm{dH}_{2}$ produced by 
Table 5. Abundances (\%, assessed by amplicon sequences of $16 \mathrm{~S}$ rRNA gene) of major bacteria in rumen fluid of dairy cows fed diets with $\mathrm{Mg}(\mathrm{OH})_{2}$ or elemental $\mathrm{Mg}(\mathrm{n}=4)$

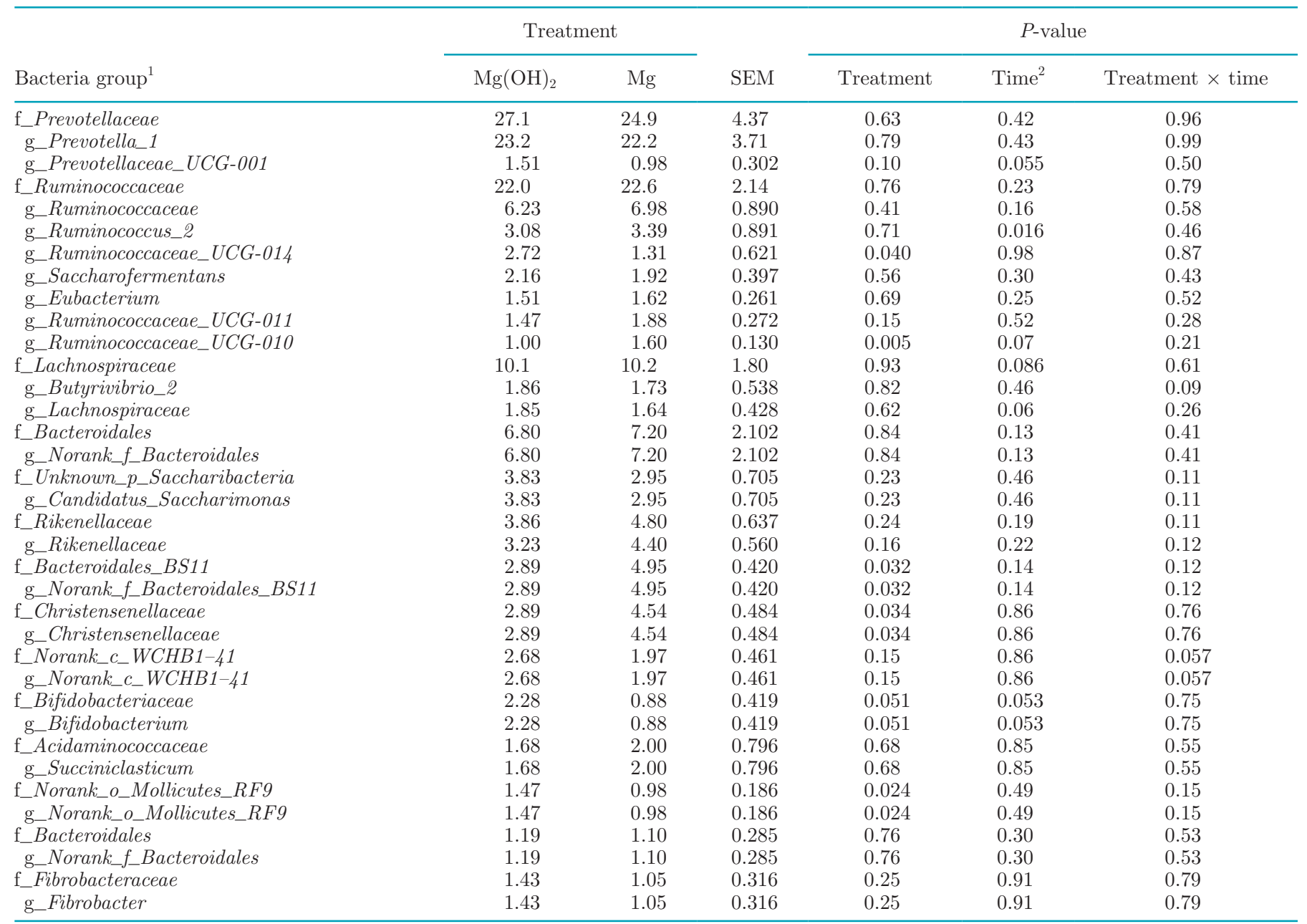

${ }_{\mathrm{f}_{-}}=$family; $\mathrm{g}_{-}=$genus.

${ }^{2}$ Relative time after morning feeding.

Table 6. Abundance (\%, assessed by amplicon sequences) and copies [ $\log _{10}$ transformed, assessed by quantitative real-time PCR (qPCR)] of $16 \mathrm{~S}$ rRNA gene of major methanogen groups in the rumen fluids of dairy cows fed diets with $\mathrm{Mg}(\mathrm{OH})_{2}$ or elemental $\mathrm{Mg}(\mathrm{n}=4)$

\begin{tabular}{|c|c|c|c|c|c|c|}
\hline Methanogen group $^{1}$ & \multicolumn{2}{|c|}{ Treatment } & SEM & \multicolumn{3}{|c|}{$P$-value } \\
\hline \multicolumn{7}{|l|}{$\begin{array}{l}\text { Relative abundance assessed by amplicon } \\
\text { sequences, } \%\end{array}$} \\
\hline o_Methanobacteriales & 98.1 & 94.3 & 0.72 & 0.005 & 0.52 & 0.29 \\
\hline $\mathrm{g} \_$Methanobrevibacter & 97.2 & 92.8 & 1.41 & 0.021 & 0.59 & 0.48 \\
\hline o_Methanomassiliicoccales & 1.75 & 5.05 & 0.737 & 0.007 & 0.75 & 0.37 \\
\hline Total methanogens & 11.0 & 11.5 & 0.08 & 0.005 & 0.21 & 0.90 \\
\hline o_Methanobacteriales & 11.0 & 11.5 & 0.06 & 0.001 & $<0.001$ & 0.38 \\
\hline g__Methanobrevibacter & 10.1 & 10.3 & 0.11 & 0.26 & 0.44 & 0.40 \\
\hline
\end{tabular}

${ }^{1} \mathrm{O}_{-}=$order; $g_{-}=$genus.

${ }^{2}$ Relative time after morning feeding. 
elemental Mg increased 16S rRNA gene copies of Methanobrevibacter by using qPCR analysis, it decreased the abundance of order Methanobacteriales (-3.48\%). Furthermore, elemental $\mathrm{Mg}$ supplementation increased the abundance of order Methanomassiliicoccales $(+188.6 \%)$, although the host animal was the major factor to separate methanogen communities. Members of the order Methanomassiliicoccales are methylotrophic methanogens and do not have the hydrogenotrophic parts of the methanogenesis pathway (Poulsen et al., 2013; Borrel et al., 2014; Li et al., 2016). It is surprising that elevated $\mathrm{dH}_{2}$ caused by $\mathrm{Mg}$ supplementation favors the growth of order Methanomassiliicoccales when compared with Methanobacteriales. The metabolism of methyl groups needs the co-factor tetrahydrofolate, which is activated by metabolic hydrogen (Maden, 2000). We speculate that more folate might be activated by elevated $\mathrm{dH}_{2}$ to carry methyl groups and generate more trimethylamine or methanol for the Methanomassiliicoccales. An increase in the abundance of Methanomassiliicoccales might explain the observed increase in $\mathrm{CH}_{4}$ emissions.

In summary, elemental $\mathrm{Mg}$ supplementation causes a pulse of elevated $\mathrm{dH}_{2}$ at $2.5 \mathrm{~h}$ after feeding, increases succinate concentration and $\mathrm{CH}_{4}$ emission, decreases feed digestibility and VFA concentration, and alters the methanogen community in dairy cows. The pulse of $\mathrm{dH}_{2}$ caused by elemental $\mathrm{Mg}$ inhibits rumen fermentation and feed digestion by decreasing carbohydrate-degrading bacteria, such as Prevotellaceae_UCG-001, Ruminococcaceae_UCG-014, and Mollicutes_RF9 groups and genus Bifidobacterium. On the other hand, the pulse of $\mathrm{dH}_{2}$ caused by elemental $\mathrm{Mg}$ promotes $\mathrm{H}_{2}$ incorporation into succinate by increasing the abundance of family Christensenellaceae and Bacteroidales_BS11 group enhances $\mathrm{H}_{2}$ utilization for methanogenesis by favoring growth of methanogens.

\section{ACKNOWLEDGMENTS}

This work was supported by National Key Research and Development Program of China (grant no. 2016YFD0500504 and 2018YFD0501800), the National Natural Science Foundation of China (grant no. 31561143009), State Key Laboratory of Animal Nutrition (grant no. 2004DA125184F1705), China Agriculture Research System (grant no. CARS-36), Youth Innovation Promotion Association CAS (grant no. 2016327), and the CAS President's International Fellowship (grant no. 2018VBA0031). The authors declare that they have no conflict of interest. Min Wang, Zhi Liang Tan, and Feng Xian Gao designed this experiment; Zhi Yuan Ma, Xiu Min Zhang, Rong Wang, and Zai Yang Jiang conducted this experiment; Zhi Yuan Ma and Min Wang analyzed the data, wrote the paper, and had primary responsibility for the final content; and Arowolo Muhammed revised the manuscript. The authors thank Emilio Ungerfeld at the Instituto de Investigaciones Agropecuarias (Vilcún, Chile) and 3 reviewers for their advice.

\section{REFERENCES}

Amato, K. R., C. J. Yeoman, A. Kent, N. Righini, F. Carbonero, A. Estrada, H. R. Gaskins, R. M. Stumpf, S. Yildirim, M. Torralba, M. Gillis, B. A. Wilson, K. E. Nelson, B. A. White, and S. R. Leigh. 2013. Habitat degradation impacts black howler monkey (Alouatta pigra) gastrointestinal microbiomes. ISME J. 7:13441353. https://doi.org/10.1038/ismej.2013.16.

AOAC. 1990. Official Method of Analysis. 15th ed. AOAC, Washington, DC.

Blackburn, T. H., and R. E. Hungate. 1963. Succinic acid turnover and propionate production in the bovine rumen. Appl. Microbiol. 11:132-135.

Borrel, G., N. Parisot, H. M. Harris, E. Peyretaillade, N. Gaci, W. Tottey, O. Bardot, K. Raymann, S. Gribaldo, P. Peyret, P. W. O'Toole, and J. F. Brugere. 2014. Comparative genomics highlights the unique biology of Methanomassiliicoccales, a Thermoplasmatales-related seventh order of methanogenic archaea that encodes pyrrolysine. BMC Genomics 15:679. https://doi.org/10 $.1186 / 1471-2164-15-679$.

Bray, J. R., and J. T. Curtis. 1957. An ordination of the upland forest communities of southern Wisconsin. Ecol. Monogr. 27:326-349.

De Nardi, R., G. Marchesini, S. Li, E. Khafipour, K. J. Plaizier, M. Gianesella, R. Ricci, I. Andrighetto, and S. Segato. 2016. Metagenomic analysis of rumen microbial population in dairy heifers fed a high grain diet supplemented with dicarboxylic acids or polyphenols. BMC Vet. Res. 12:29. https://doi.org/10.1186/s12917-016 -0653-4.

Denman, S. E., and C. S. McSweeney. 2006. Development of a realtime PCR assay for monitoring anaerobic fungal and cellulolytic bacterial populations within the rumen. FEMS Microbiol. Ecol. 58:572-582. https://doi.org/10.1111/j.1574-6941.2006.00190.x.

Gagen, E. J., J. Wang, J. Padmanabha, J. Liu, I. P. de Carvalho, J. Liu, R. I. Webb, J. R. Al, M. Morrison, S. E. Denman, and C. S. McSweeney. 2014. Investigation of a new acetogen isolated from an enrichment of the tammar wallaby forestomach. BMC Microbiol. 14:314. https://doi.org/10.1186/s12866-014-0314-3.

Goel, G., and H. P. S. Makkar. 2012. Methane mitigation from ruminants using tannins and saponins. Trop. Anim. Health Prod. 44:729-739. https://doi.org/10.1007/s11250-011-9966-2.

Grant, R. J., and D. R. Mertens. 1992. Influence of buffer $\mathrm{pH}$ and raw corn starch addition on in vitro fiber digestion kinetics. J. Dairy Sci. 75:2762-2768. https://doi.org/10.3168/jds.S0022 -0302(92)78039-4.

He, Y., W. Niu, Q. Qiu, C. Xia, T. Shao, H. Wang, Q. Li, Z. Yu, Z Gao, M. Rahman, H. Su, and B. Cao. 2017. Effect of calcium salt of long-chain fatty acids and alfalfa supplementation on performance of Holstein bulls. Oncotarget 9:3029-3042. https://doi.org/ 10.18632/oncotarget.23073.

Hook, S. E., A. D. Wright, and B. W. McBride. 2010. Methanogens: Methane producers of the rumen and mitigation strategies. Archaea 2010:945785. https://doi.org/10.1155/2010/945785.

Huang, X. D., G. Martinez-Fernandez, J. Padmanabha, R. Long, S. E. Denman, and C. S. McSweeney. 2016. Methanogen diversity in indigenous and introduced ruminant species on the Tibetan Plateau. Archaea 2016:5916067. https://doi.org/10.1155/2016/5916067.

Hungate, R. E. 1967. Hydrogen as an intermediate in the rumen fermentation. Arch. Mikrobiol. 59:158-164.

Janssen, P. H. 2010. Influence of hydrogen on rumen methane formation and fermentation balances through microbial growth kinetics and fermentation thermodynamics. Anim. Feed Sci. Technol. 160:1-22. https://doi.org/10.1016/j.anifeedsci.2010.07.002. 
Karthner, R. J., and B. Theurer. 1981. Comparison of hydrolysis methods used in feed, digesta, and fecal starch analysis. J. Agric. Food Chem. 29:8-11. https://doi.org/10.1021/jf00103a003.

Kim, C. C. 2012. Identification of rumen methanogens, characterization of substrate requirements and measurement of hydrogen thresholds. Master's thesis. Microbiology, Massey University, Palmerston North, New Zealand.

Kozich, J. J., S. L. Westcott, N. T. Baxter, S. K. Highlander, and P. D. Schloss. 2013. Development of a dual-index sequencing strategy and curation pipeline for analyzing amplicon sequence data on the MiSeq Illumina sequencing platform. Appl. Environ. Microbiol. 79:5112-5120. https://doi.org/10.1128/AEM.01043-13.

Li, Y., S. C. Leahy, J. Jeyanathan, G. Henderson, F. Cox, E. Altermann, W. J. Kelly, S. C. Lambie, P. H. Janssen, J. Rakonjac, and G. T. Attwood. 2016. The complete genome sequence of the methanogenic archaeon ISO4-H5 provides insights into the methylotrophic lifestyle of a ruminal representative of the Methanomassiliicoccales. Stand. Genomic Sci. 11:59. https://doi.org/10.1186/ s40793-016-0183-5.

Lovley, D. R., and J. G. Ferry. 1985. Production and consumption of $\mathrm{H}_{2}$ during growth of Methanosarcina spp. on acetate. Appl. Environ. Microbiol. 49:247-249.

Ma, Z., R. Wang, M. Wang, X. Zhang, H. Mao, and Z. Tan. 2018. Short communication: Variability in fermentation end-products and methanogen communities in different rumen sites of dairy cows. J. Dairy Sci. 101:5153-5158. https://doi.org/10.3168/jds 2017-14096.

Maden, B. E. 2000. Tetrahydrofolate and tetrahydromethanopterin compared: Functionally distinct carriers in $\mathrm{C} 1$ metabolism. Biochem. J. 350:609-629

Maekawa, M., K. A. Beauchemin, and D. A. Christensen. 2002. Effect of concentrate level and feeding management on chewing activities, saliva production, and ruminal $\mathrm{pH}$ of lactating dairy cows. J. Dairy Sci. 85:1165-1175. https://doi.org/10.3168/jds.S0022 $-0302(02) 74179-9$.

Martinez-Fernandez, G., S. Duval, M. Kindermann, H. J. Schirra, S. E. Denman, and C. S. McSweeney. 2018. 3-NOP vs. halogenated compound: Methane production, ruminal fermentation and microbial community response in forage fed cattle. Front. Microbiol. 9:1582. https://doi.org/10.3389/fmicb.2018.01582.

Miller, T. L., and M. J. Wolin. 1995. Bioconversion of cellulose to acetate with pure cultures of Ruminococcus albus and a hydrogenusing acetogen. Appl. Environ. Microbiol. 61:3832-3835.

Minas, K., N. R. McEwan, C. J. Newbold, and K. P. Scott. 2011. Optimization of a high-throughput CTAB-based protocol for the extraction of qPCR-grade DNA from rumen fluid, plant and bacterial pure cultures. FEMS Microbiol. Lett. 325:162-169. https://doi .org/10.1111/j.1574-6968.2011.02424.x.

NRC. 2001. Nutrient Requirements of Dairy Cattle: Seventh Revised Edition. National Research Council, Washington, DC.

Olijhoek, D. W., A. L. F. Hellwing, M. R. Weisbjerg, J. Dijkstra, O. H. Jberg, and P. Lund. 2016. Effect of short-term infusion of hydrogen on enteric gas production and rumen environment in dairy cows. Anim. Prod. Sci. 56:466. https://doi.org/10.1071/AN15521.

Pires, A. C., D. F. Cleary, A. Almeida, A. Cunha, S. Dealtry, L. C. Mendonca-Hagler, K. Smalla, and N. C. Gomes. 2012. Denaturing gradient gel electrophoresis and barcoded pyrosequencing reveal unprecedented archaeal diversity in mangrove sediment and rhizosphere samples. Appl. Environ. Microbiol. 78:5520-5528. https:// doi.org/10.1128/AEM.00386-12.

Poulsen, M., C. Schwab, B. B. Jensen, R. M. Engberg, A. Spang, N. Canibe, O. Hojberg, G. Milinovich, L. Fragner, C. Schleper, W. Weckwerth, P. Lund, A. Schramm, and T. Urich. 2013. Methylotrophic methanogenic Thermoplasmata implicated in reduced methane emissions from bovine rumen. Nat. Commun. 4:1428 https://doi.org/10.1038/ncomms2432.

Qiao, J. Y., Z. L. Tan, L. L. Guan, S. X. Tang, C. S. Zhou, X. F. Han, M. Wang, J. H. Kang, and Z. X. He. 2015. Effects of hydrogen in headspace and bicarbonate in media on rumen fermentation, methane production and methanogenic population using in vitro gas production techniques. Anim. Feed Sci. Technol. 206:19-28. https://doi.org/10.1016/j.anifeedsci.2015.05.004.

Quast, C., E. Pruesse, P. Yilmaz, J. Gerken, T. Schweer, P. Yarza, J. Peplies, and F. O. Glockner. 2013. The SILVA ribosomal RNA gene database project: Improved data processing and web-based tools. Nucleic Acids Res. 41:D590-D596. https://doi.org/10.1093/ nar/gks1219.

Quillian, E. R., W. J. Miller, R. P. Gentry, S. R. Heinmiller, and M. W. Neathery. 1980. Maximum safe dietary magnesium and effects of high dietary magnesium on zinc metabolism in Holstein calves. J. Dairy Sci. 63:457-463. https://doi.org/10.3168/jds.S0022 -0302(80)82953-5.

Robinson, J. A., and J. M. Tiedje. 1982. Kinetics of hydrogen consumption by rumen fluid, anaerobic digestor sludge, and sediment. Appl. Environ. Microbiol. 44:1374-1384.

Rother, M., and J. A. Krzycki. 2010. Selenocysteine, pyrrolysine, and the unique energy metabolism of methanogenic archaea. Archaea 2010:453642. https://doi.org/10.1155/2010/453642.

Schloss, P. D., S. L. Westcott, T. Ryabin, J. R. Hall, M. Hartmann, E. B. Hollister, R. A. Lesniewski, B. B. Oakley, D. H. Parks, C. J. Robinson, J. W. Sahl, B. Stres, G. G. Thallinger, D. J. Van Horn, and C. F. Weber. 2009. Introducing mothur: Open-source, platform-independent, community-supported software for describing and comparing microbial communities. Appl. Environ. Microbiol. 75:7537-7541. https://doi.org/10.1128/AEM.01541-09.

Shahinian, A. H., and J. G. Reinhold. 1971. Application of the phenol-hypochlorite reaction to measurement of ammonia concentrations in Kjeldahl digests of serum and various tissues. Clin. Chem. 17:1077-1080. https://doi.org/10.1021/ac60252a045.

Solden, L. M., D. W. Hoyt, W. B. Collins, J. E. Plank, R. A. Daly, E. Hildebrand, T. J. Beavers, R. Wolfe, C. D. Nicora, S. O. Purvine, M. Carstensen, M. S. Lipton, D. E. Spalinger, J. L. Firkins, B. A. Wolfe, and K. C. Wrighton. 2017. New roles in hemicellulosic sugar fermentation for the uncultivated Bacteroidetes family BS11. ISME J. 11:691-703. https://doi.org/10.1038/ismej.2016.150.

Svartstrom, O., J. Alneberg, N. Terrapon, V. Lombard, I. de Bruijn, J. Malmsten, A. M. Dalin, M. E. El, P. Shah, P. Wilmes, B. Henrissat, H. Aspeborg, and A. F. Andersson. 2017. Ninety-nine de novo assembled genomes from the moose (Alces alces) rumen microbiome provide new insights into microbial plant biomass degradation. ISME J. 11:2538-2551. https://doi.org/10.1038/ismej.2017 108 .

Thoetkiattikul, H., W. Mhuantong, T. Laothanachareon, S. Tangphatsornruang, V. Pattarajinda, L. Eurwilaichitr, and V. Champreda. 2013. Comparative analysis of microbial profiles in cow rumen fed with different dietary fiber by tagged $16 \mathrm{~S}$ rRNA gene pyrosequencing. Curr. Microbiol. 67:130-137. https://doi.org/10.1007/s00284 -013-0336-3.

Trovatelli, L. D., and D. Matteuzzi. 1976. Presence of bifidobacteria in the rumen of calves fed different rations. Appl. Environ. Microbiol. 32:470-473.

Ungerfeld, E. M. 2013. A theoretical comparison between two ruminal electron sinks. Front. Microbiol. 4:319. https://doi.org/10.3389/ fmicb. 2013.00319.

Ungerfeld, E. M. 2015. Corrigendum: Shifts in metabolic hydrogen sinks in the methanogenesis-inhibited ruminal fermentation: A meta-analysis. Front. Microbiol. 6:538. https://doi.org/10.3389/ fmicb.2015.00538

Ungerfeld, E. M., and R. A. Kohn. 2006. The role of thermodynamics in control of ruminal fermentation. Pages 55-85 in Ruminant Physiology. Digestion, Metabolism and Impact of Nutrition on Gene Expression, Immunology and Stress. K. H. T. N. Sejrsen, ed. Wageningen Academic Publishers, Wageningen, the Netherlands.

Van Soest, P. J., J. B. Robertson, and B. A. Lewis. 1991. Methods for dietary fiber, neutral detergent fiber, and nonstarch polysaccharides in relation to animal nutrition. J. Dairy Sci. 74:3583-3597. https://doi.org/10.3168/jds.S0022-0302(91)78551-2.

Wang, M., X. Z. Sun, P. H. Janssen, S. X. Tang, and Z. L. Tan. 2014 Responses of methane production and fermentation pathways to the increased dissolved hydrogen concentration generated by eight 
substrates in in vitro ruminal cultures. Anim. Feed Sci. Technol. 194:1-11. https://doi.org/10.1016/j.anifeedsci.2014.04.012.

Wang, M., R. Wang, P. H. Janssen, X. M. Zhang, X. Z. Sun, D. Pacheco, and Z. L. Tan. 2016a. Sampling procedure for the measurement of dissolved hydrogen and volatile fatty acids in the rumen of dairy cows. J. Anim. Sci. 94:1159-1169. https://doi.org/10.2527/ jas.2015-9658.

Wang, M., R. Wang, M. Liu, K. A. Beauchemin, X. Z. Sun, S. X. Tang, J. Z. Jiao, and Z. L. Tan. 2018. Dietary starch and rhubarb supplement increase ruminal dissolved hydrogen without altering rumen fermentation and methane emissions in goats. Animal https://doi .org/10.1017/S1751731118002410.

Wang, M., R. Wang, X. Sun, L. Chen, S. Tang, C. Zhou, X. Han, J. Kang, Z. Tan, and Z. He. 2015. A mathematical model to describe the diurnal pattern of enteric methane emissions from non-lactating dairy cows post-feeding. Anim. Nutr. 1:329-338. https://doi .org/10.1016/j.aninu.2015.11.009.

Wang, M., R. Wang, T. Y. Xie, P. H. Janssen, X. Z. Sun, K. A Beauchemin, Z. L. Tan, and M. Gao. 2016b. Shifts in rumen fermentation and microbiota are associated with dissolved ruminal hydrogen concentrations in lactating dairy cows fed different types of carbohydrates. J. Nutr. 146:1714-1721. https://doi.org/10 $.3945 /$ jn. 116.232462

Wang, M., R. Wang, X. Zhang, E. M. Ungerfeld, D. Long, H. Mao, J. Jiao, K. A. Beauchemin, and Z. Tan. 2017. Molecular hydrogen generated by elemental magnesium supplementation alters rumen fermentation and microbiota in goats. Br. J. Nutr. 118:401-410. https://doi.org/10.1017/S0007114517002161.
Wang, Q., G. M. Garrity, J. M. Tiedje, and J. R. Cole. 2007. Naive Bayesian classifier for rapid assignment of rRNA sequences into the new bacterial taxonomy. Appl. Environ. Microbiol. 73:52615267. https://doi.org/10.1128/AEM.00062-07.

Weimer, P. J. 1998. Manipulating ruminal fermentation: A microbial. J. Anim. Sci. 76:3114-3122.

Wenner, B. A., S. J. De, F. Batistel, T. J. Hackmann, Z. Yu, and J. L. Firkins. 2017. Association of aqueous hydrogen concentration with methane production in continuous cultures modulated to vary $\mathrm{pH}$ and solids passage rate. J. Dairy Sci. 100:5378-5389.

Yang, W. Z., K. A. Beauchemin, and L. M. Rode. 2001. Effects of grain processing, forage to concentrate ratio, and forage particle size on rumen $\mathrm{pH}$ and digestion by dairy cows. J. Dairy Sci. 84:2203-2216. https://doi.org/10.3168/jds.S0022-0302(01)74667-X.

Yu, Y., C. Lee, J. Kim, and S. Hwang. 2005. Group-specific primer and probe sets to detect methanogenic communities using quantitative real-time polymerase chain reaction. Biotechnol. Bioeng. 89:670-679. https://doi.org/10.1002/bit.20347.

Yu, Z., and M. Morrison. 2004. Improved extraction of PCR-quality community DNA from digesta and fecal samples. Biotechniques 36:808-812. https://doi.org/10.2144/04365ST04.

Zhang, X., and L. Wang. 2018. Effect of dietary neutral detergent fiber level on structure and composition of rumen bacteria in goats [in Chinese]. Chin. J. Anim. Nutr. https://doi.org/10.3969/j.issn.1006 $-267 x .2018 .04 .020$. 